Z. klin. Chem. u. klin. Biochem.

10. Jg. 1972 , S. $169-170$

\title{
Anwendung monospezifischer heterophiler Präzipitine in der quantitativen Immunelektrophorese
}

\author{
Von G. Uhlenbruck, W. Stephan und Ina Sprenger \\ Aus der Medizinischen Universitätsklinik, Abteilung Immunbiologie, Köln und der Wissenscbaftlichen Abteilung \\ der Biotest-Serum-Institut GmbH Frankfurt/Main
}

(Eingegangen am 17. Dezember 1971)

Die diagnostischen Möglichkeiten der quantitativen Immunelektrophorese können durch Einbeziehung monospezifischer heterophiler Präzipitine aus Pflanzen und Avertebraten beträchtlich erweitert werden, wic am Beispiel der Blutgruppensubstanz A und des Präzipitins aus der Eiweißdrüse von Helix pomatia demonstriert wird.

\section{The use of monospecific beteropbilic precipitins in quantitative inmunoelectrophoresis}

The diagnostic possibilities of quantitative immunoelectrophoresis can be considerably extended by using monospecific heterophilic agglutinins from plants and invertebrates. This is demonstrated by blood-group-A-substance and the agglutinin from the albumin gland of Helix pomatia.

Auf die Bedeutung der zweidimensionalen LAURELLElektrophorese für die klinische Diagnostik und forensische Medizin, insbesondere als Mikromethode durch quantitative Simultan-Immunelektrophorese, ist in vorhergehenden Arbeiten hingewiesen worden $(1,2)$. In dieser Mitteilung soll nun darüber berichtet werden, daß bei dieser Technik nicht nur Antiseren (Immunglobuline) angewandt werden können, sondern auch heterophile präzipitierende antikörperähnliche Substanzen aus Pflanzen (Lektine) und Avertebraten (Protektine), die in der Regel monospezifisch gegen vorwiegend endständige terminal angeordnete Kohlenhydratstrukturen gerichtet sind (3). Als Beispiel soll hier das Verhalten des Anti-A Präzipitins aus der Eiweißdrüse der Weinbergschnecke Helix pomatia gegenüber Blutgruppensubstanz $\mathrm{A}$ aus Pepton demonstriert werden.

\section{Material und Methodik}

Blutgruppensubstanz $A$ wurde durch Phenol-NaCl-Extraktion aus Pepton $S$ der Firma Brunnengtäber (Lübeck) hergestellt (4).

Helix pomatia-Extrakt wurde aus Eiweißdrüsen der Weinbergschnecke Helix pomatia isoliert wie früher beschrieben (5).

Quantitative Immunelektropborese: aufgetrennt wurden 1,5 $\mu \mathrm{l}$ einer 2,5proz. Lösung der Blutgruppenșubstanz $\mathrm{A}$ in physiol. $\mathrm{NaCl}$ Lösung.

Die „Antikörper"-haltige Agarose bestand aus $0,25 \mathrm{ml}$ des Helix-pomatia-Extraktes in der Verdünnung 1:2, 1:4 und 1:8, $1,4 \mathrm{ml}$ Barbituratpuffer, 0,075 $\mathrm{M}, \mathrm{pH} 8,6$ und 1,4 ml eines 2proz. wäßr. Agarose-Gels.

Die Analyse wurde in der „Meath"-Elektrophorese-Kammer (Hersteller: Fa. Paines und Bytne, Greenford, England) mit einem Puffervolumen von 3 Litern je Tank und Temperierung auf $23^{\circ}$ durch Wasserkühlung durchgeführt. Die erste Dimension dauerte $3 \mathrm{Stdn}$. bei 200 Volt $=15 \mathrm{~mA}$; das entsprach einer Auftrennstrecke des Albumins von $2,0 \mathrm{~cm}$ in einer mitgeführten Kontrollanalyse von Serum. Für die zweite Dimension wurden $20 \mathrm{Stdn}$. bei 200 Volt $=15 \mathrm{~mA}$ benötigt.

\section{Ergebnisse und Diskussion}

Abbildung 1 zeigt, daß die Darstellung der Blutgruppensubstanz A als Antigen durch den Helix pomatia-Extrakt als "Antiserum" in der quantitativen Immunelektrophorese möglich ist und $\mathrm{da} ß$ eine quantitative Auswertung zulässig ist. Die durch Helix pomatia-Extrakt als "Antiserum" in den Verdünnungen $1: 2,1: 4$ und $1: 8$ dargestellten Peaks der Blutgruppensubstariz A entsprechen in ihrer Fläche (Wägemethode) dem Verdünnungsausmaß: die Kurve ist annähernd linear (Abb. 3). Abbildung 2 (eine Photomontage) zeigt, daß die A-Substanz eine Beweglichkeit zwischen IgG und Transferrin hat.

Die vorliegenden Ergebnisse sagen, daß sich heterophile präzipitierende Agglutinine bzw. antikörperähnliche Substanzen für die zweidimensionale LAURELLElektrophorese eignen. Der Anwendungsbereich dieser erweiterten Methodik ist evident:

1. Es lassen sich quantitative vergleichende Bestimmungen von verschiedenen Substanzen mit gleicher serologischer Spezifität bzw. Kohlenhydratstruktur durchführen. Im vorliegenden Fall wären dies

a) verschiedene Substanzen mit Blutgruppen-A-Spezifität bzw. $\alpha$-glykosidisch gebundenem N-Acetyl-DGalaktosamin sowie heterophile blutgruppen-A-aktive Verbindungen aus Tubifex, Magenschleimhaut, von Tieren (Schwein), Bakterien, aus Ovarcysten, Sperma, Forssman Antigene u. a.

b) Glykoproteine, welche nach Abspaltung endständiger Neuraminsäure dieses Hexosamin in terminaler Position aufweisen (neuraminidase-behandelte Erythrocytenmucoide, Submaxillarismucin u. a. m.).

2. Prinzipiell gleiche Uberlegungen gelten für andere heterophile Präzipitine, z. B. dasjenige aus Samen der 
$\mathbf{a}$
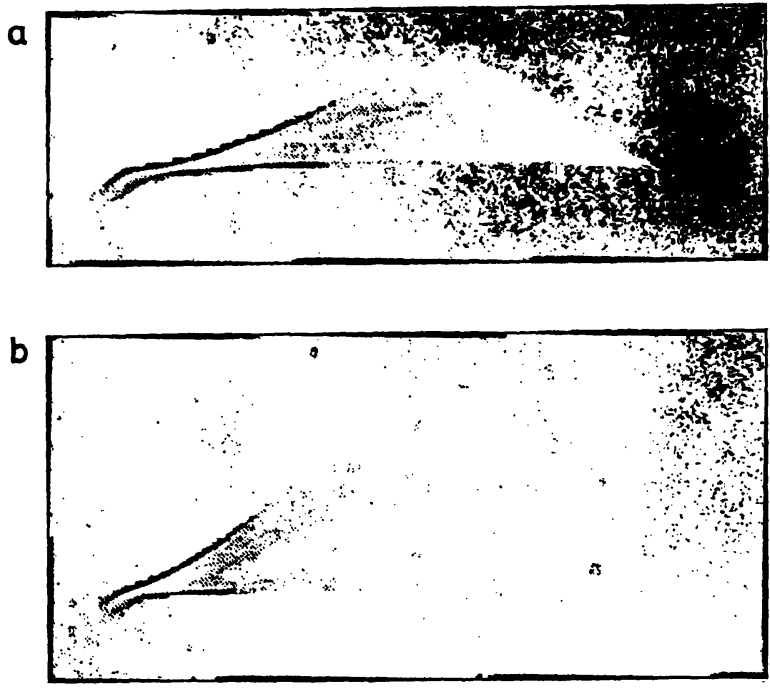

C

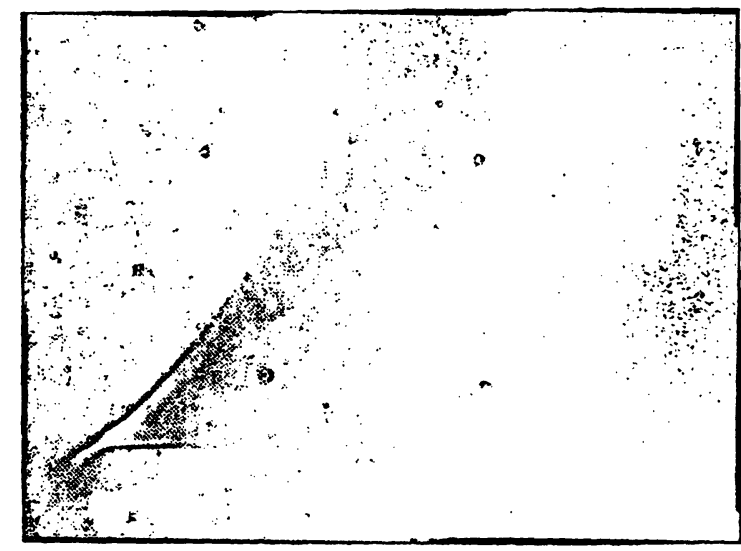

I. Dimension

Abb. 1

LAURELL-Elektrophorese: Blutgruppensubstanz A dargestellt mit Helix pomatia-Extrakt in verschiedenen Verdünnungen: a: $1: 2$, b: $1: 4, c: 1: 8$

Pflanze Ricinus communis, welches mit terminalen $\beta$ Galaktosido-Strukturen reagiert. Verschiedene normale und neuraminidase-behandelte Glykoproteine werden hierdurch präzipitiert. Besonders interessant ist in diesem Zusammenhang, daß sich in einem Gemisch von Proteinen und Glykoproteinen die letzteren auf diese Weise selektiv darstellen lassen. $\mathrm{Zu}$ diesem Zwecke wären aus einer Probe zwei Pherogramme anzufertigen, von denen das eine mit einem spezi-

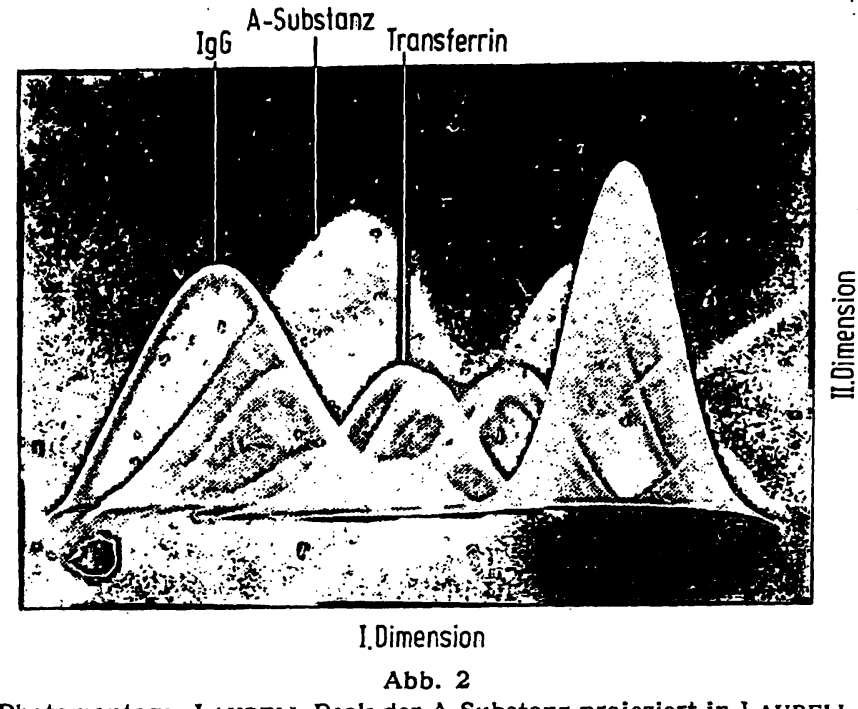

Photomontage: LAURELL-Peak der A-Substanz projeziert in LAURELLElektrophoretische Auftrennung eines Normal-Humanserums

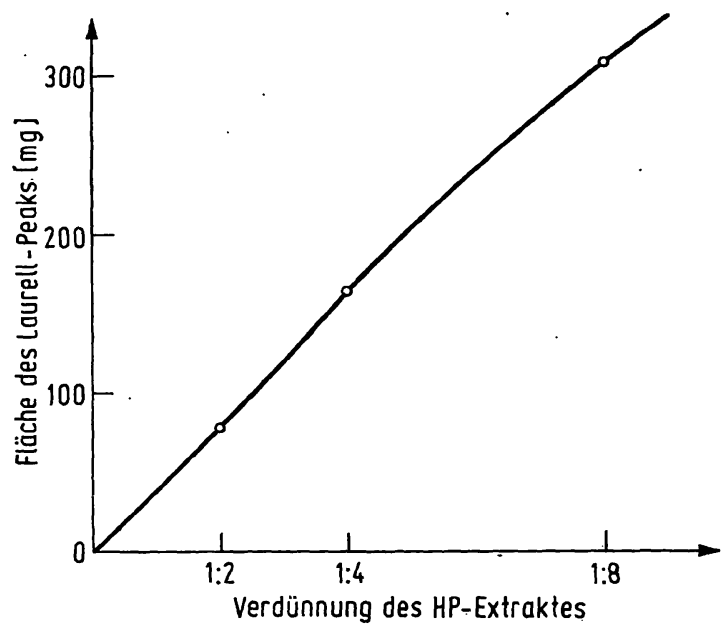

Abb. 3 Einfluß der Konzentration des ,Antiserums“" (Helix pomatia (HP)A. Die Peakflächen wurden ausgeschnitten und gewogen

fischen Antiserum, das andere mit einem heterophilen Präzipitin entwickelt werden müßte. Die Beweglichkeiten wären dann in einer Photomontage (siehe Abb. 2) vergleichbar.

3. Durch Anwendung der umgekehrten Technik und Einsatz von Helix pomatia-Extrakt als Antigen und A-Substanz als "Antiserum" kanin außerdem Aufschluß über die Heterogenität dieser antikörperähnlichen Substanzen gewonnen werden.

\section{Literatur}

1. Stephan, W. und U. Frahm, diese Z. 8, 469 (1970). - 2. StepHAN, W. und U. FrAHM, diese Z. 9, 224 (1971). - 3. UHLENBRUCK, G., „Immunbiologie“, Wilhelm Goldmann Verlag,
München (1971). - 4. Uhlenbruck, G., I. SpRenger und G. I. Pardoe, Z. Immun.-Forsch. 140, 496 (1970). - 5. UhlenBruCK, G., Hoppe-Seylers Z. physiol. Chem. 356, 672 (1969).

Prof. Dr. G. Uhlenbruck und Dr. I. Sprenger Abteilung Immunbiologie 5 Köln 41

Kerpener Str. 15

Dr. W. Stephan

6 Frankfurt-Niederrad

Flughafenstr. 4 